\title{
An Application of Fourier Transform Infrared (FT-IR) Microspectroscopy to the Study of Cigarette Manufacturing Defects*
}

\author{
by \\ M. M. Thompson and M. S. Ireland \\ Lorillard Tobacco Company, \\ 420 English Street, \\ Greensboro, NC 27420, U.S.A.
}

SUMMARY

FT-IR microspectroscopy was used to investigate a common type of cigarette defect in which the filter separates from the tobacco rod. Infrared imagings of the adhesive located at this junction on the tipping papers from both defective and acceptable cigarettes were obtained. A comparison of these data revealed that although adhesive was present in the seam area of the defective cigarettes, the amount of adhesive was significantly less and its distribution was not uniform.

\section{ZUSAMMENFASSUNG}

Mittels Infrarotspektroskopie wurde ein häufig auftretender Cigarettenfilterdefekt untersucht, bei dem sich der Filter vom Tabakstrang löst. Infrarotaufnahmen zeigten das Klebemittel an dieser Verbindungsstelle des Filtermundstückbelags von beschädigten und unbeschädigten Cigaretten. Ein Vergleich der Daten ergab, daß bei beschädigten Cigaretten zwar auch Klebemittel vorhanden war, jedoch bedeutend weniger und in ungleichmäßiger Verteilung.

\footnotetext{
* Received: 2nd June 1991 - accepted 14th November 1991
}

\section{RESUME}

La méthode FT-IR (spectroscopie IR/transformation de Fourier) a été utilisée pour examiner un défaut fréquemment rencontré dans les cigarettes, à savoir la séparation du bout-filtre et du cordon de tabac. On a ainsi réalisé des images infra-rouges des adhésifs placés sur les manchettes à la jonction filtre/cordon dans le cas de cigarettes défectueuses et de cigarettes acceptables. La comparaison des valeurs obtenues a montré que les cigarettes défectueuses présentaient aussi de l'adhésif dans la zone d'assemblage, mais que la quantité en était nettement inférieure et la distribution non uniforme.

\section{INTRODUCTION}

Cigarette manufacturing is a complex process requiring many different and relatively small components to be assembled with precise accuracy. To understand problems associated with the manufacture of this product, sensitive analytical techniques capable of providing chemical information describing observed defects are essential.

During the past six years, FT-IR microspectroscopy has become a powerful tool widely used in failure analysis. The advantages of this technique are clear. Infrared spectroscopy provides a non-destructive method for determining molecular or functional group information 
about materials and the possibility of their quantitative evaluation; the microscope accessory enables this information to be measured for extremely small samples or small regions within larger samples. Recently, this technique has been used as an imaging probe in which spatially specific infrared spectra were used to generate functional group maps (1-5). The IR imaging process begins with the collection of a series of infrared spectra measured at specific X-and Y-spatial positions on the sample. This four-dimensional data array (X- vs. Y- vs. frequency vs. IR intensity) is then compressed to three-dimensions by monitoring the IR intensity of a single frequency for the spatial range of the sample. Thus, by selecting a frequency specific to a functional group of a targeted material, an image of this material's spatial distribution over the sample is obtained.

In this report, the technique of FT-IR microspectroscopy imaging is used to investigate a manufacturing defect known as "filter fall-off." As the term suggests, filter falloff cigarettes are those in which the filter has separated from the tobacco rod. This occurs when the adhesive on the circumscribing tipping paper forms an imperfect seal with the cigarette paper; this seam occupies only a $4 \mathrm{~mm} \times 25 \mathrm{~mm}$ area. To characterize this product defect, FT-IR microspectroscopy was used to (1) determine the level of adhesive present at the tipping/cigarette paper junction, and (2) determine the spatial distribution of the adhesive in this small area.

\section{Figure 1.}

Representative Micro-FT-IR spectra of tipping paper adhesive seams from A and B control cigarette samples.
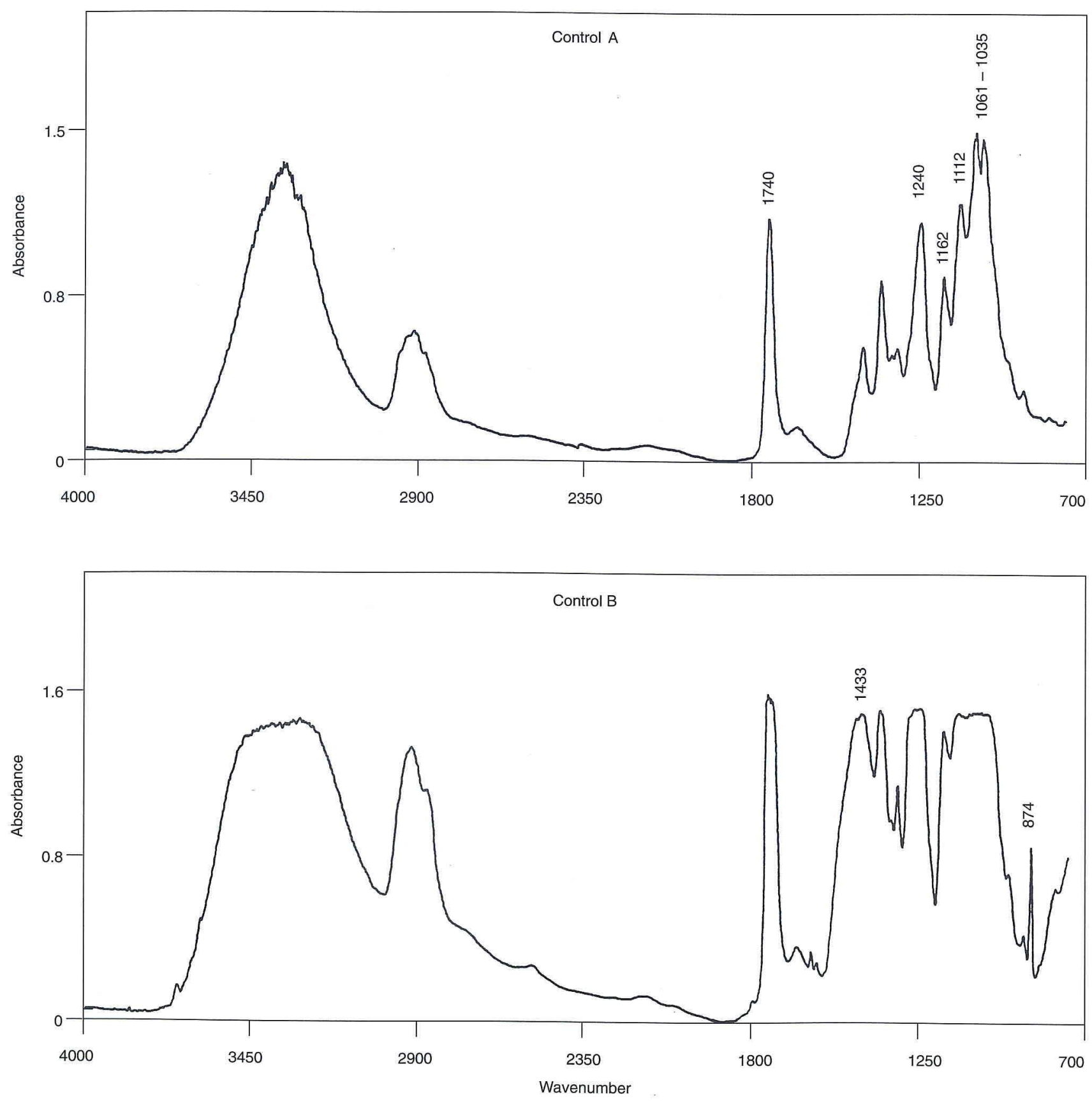
Figure 2.

Infrared microspectroscopy image plots obtained from 4-mm spectral rows measured at the edge and central areas of the 25-mm tipping paper seams of control samples A and B. The image is based upon the $1740-\mathrm{cm}^{-1}$ absorption frequency characteristic of PVA.

\section{Control A}
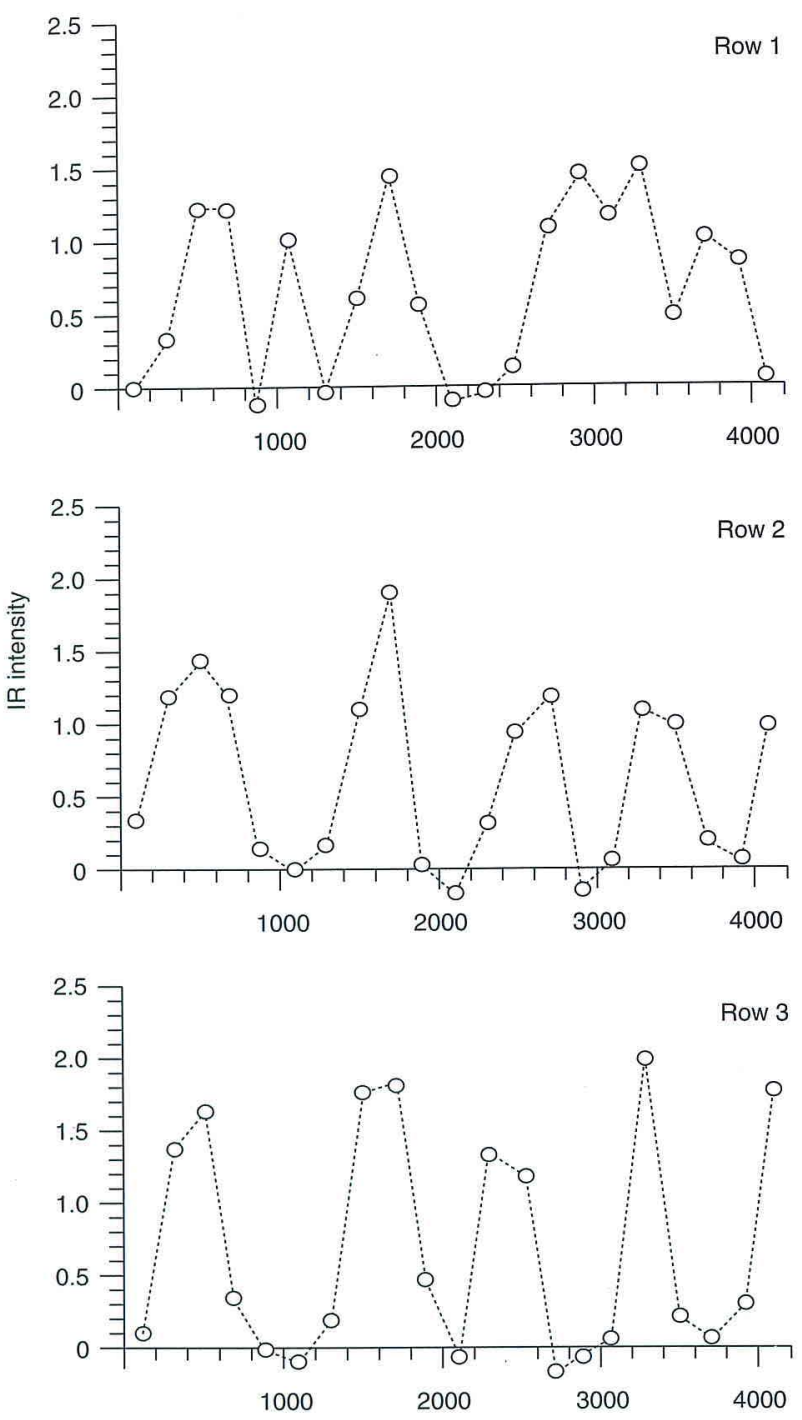

Paper interior distance $(\mu \mathrm{m})$

\section{MATERIALS AND METHODS}

\section{Cigarette Sample}

Cigarette samples from two different commercial cigarette brands, denoted as A (2 samples) and B (3 samples), exhibiting filter fall-off defects were obtained for analysis from consumer returns. In each sample, the tipping paper was intact, unattached to the filter and to virtually any cigarette paper. For the IR analysis, the adhesive seam area of the tipping paper was mounted squarely across the opening of an IR microscope window holder.

Control samples consisted of commercially acceptable cigarettes selected from corresponding cigarette brands. In order to expose the tipping/cigarette paper glue seam, the joined papers of the control cigarettes were first
Control B
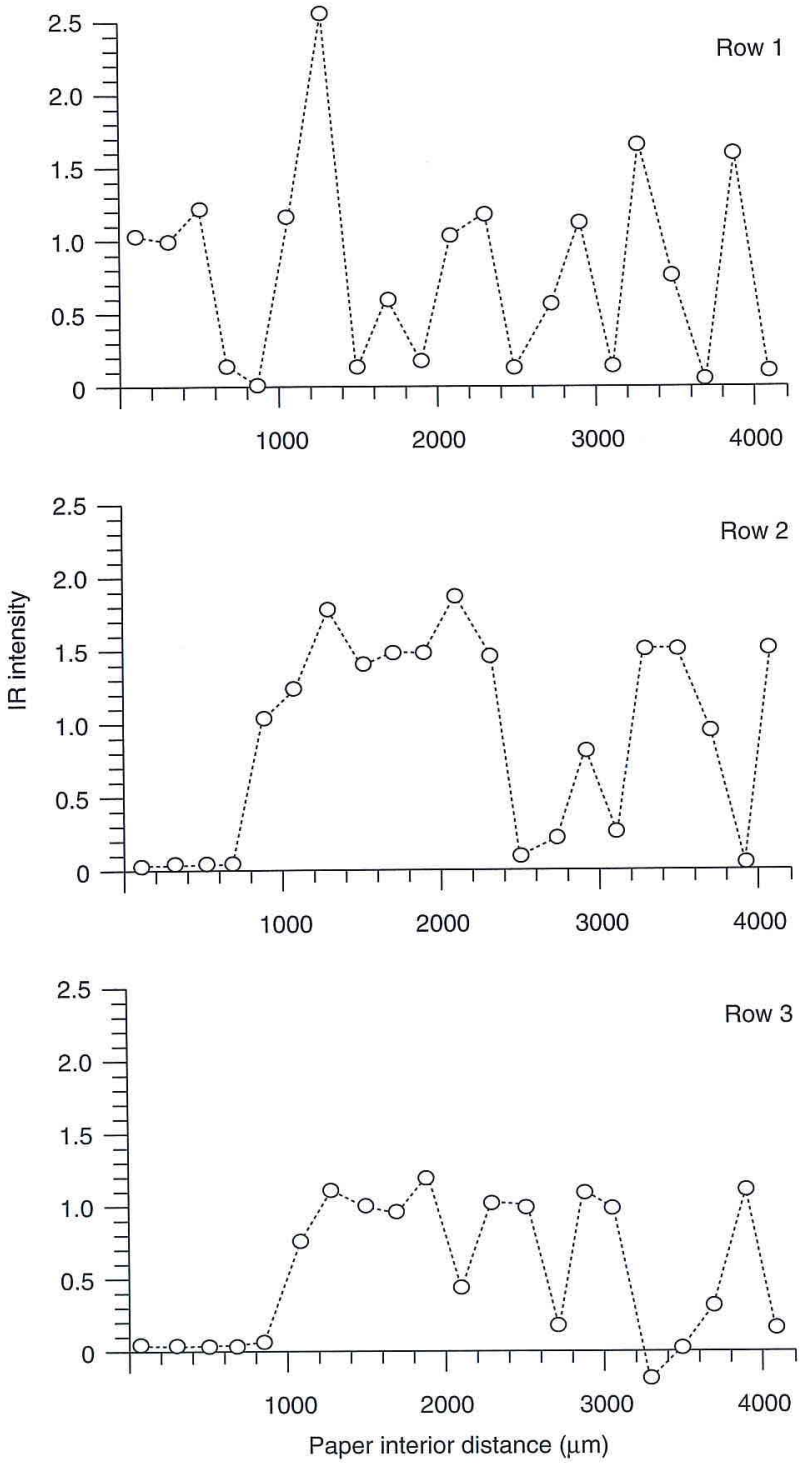

removed from the tobacco and filter, humidified, and then carefully pulled apart. Since these examples of tipping paper were from effective seams, some of the adhesive was assumed to be lost to the detached cigarette paper; therefore, these samples theoretically exhibited the leastto-most possible adhesive present on a given tipping paper seam. The adhesive used in all samples was polyvinyl acetate, hereafter referred to as PVA.

\section{FT-IR Microscopy Analysis}

IR spectra were collected with a Nicolet 7199 FT-IR spectrometer interfaced to a Spectra-Tech IR-PLAN microscope. 
Figure 3.

Comparison plots of average infrared microspectroscopy image rows obtained for both brand $A$ and $B$ control (-O-) and filter fall-off samples (--) A1, A2; B1, B2 and B3. Each plot represents the average IR intensity value at $1740-\mathrm{cm}^{-1}$ of three data arrays obtained from the middle and opposite edges of a single adhesive seam.
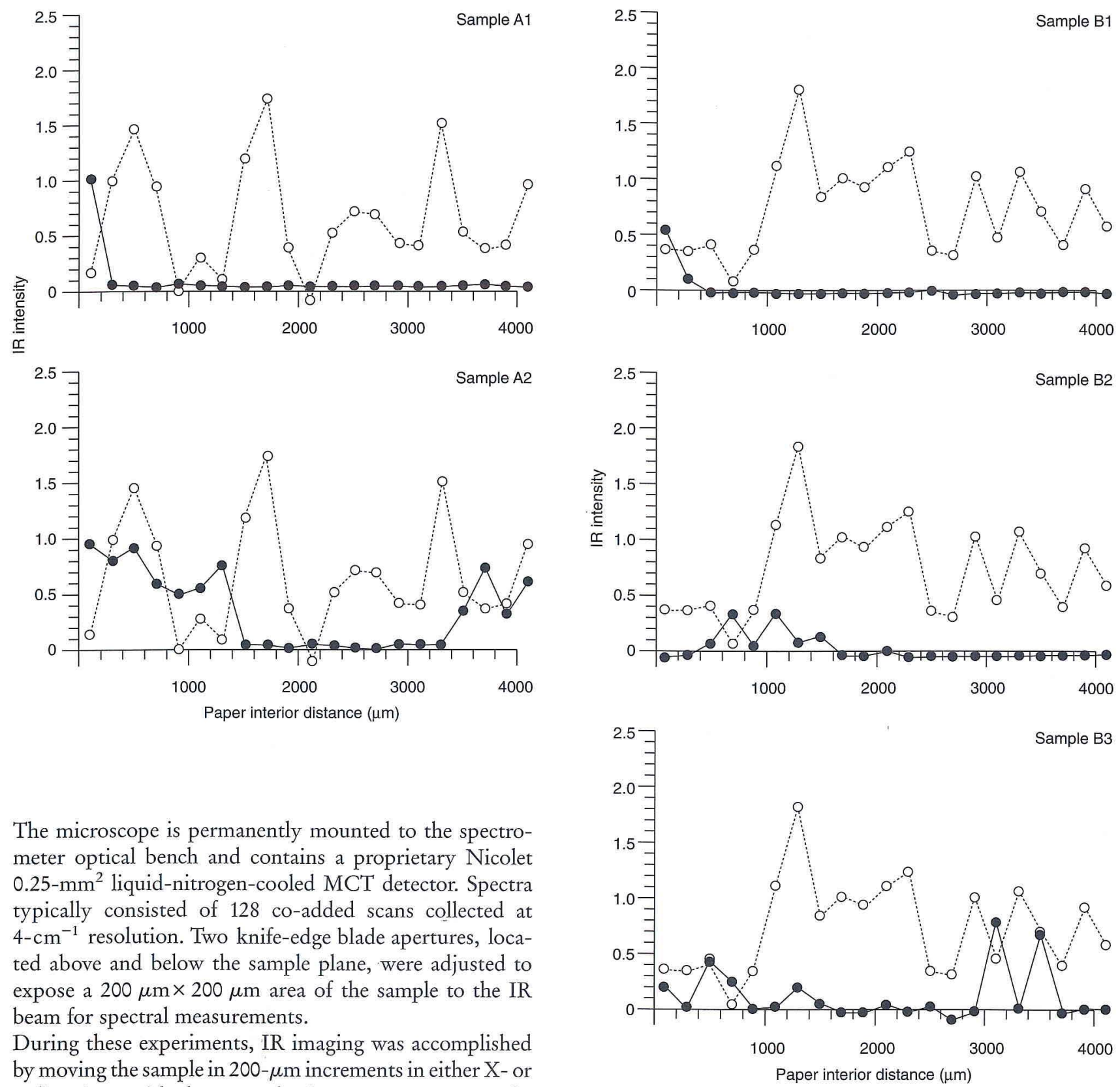

The microscope is permanently mounted to the spectrometer optical bench and contains a proprietary Nicolet $0.25-\mathrm{mm}^{2}$ liquid-nitrogen-cooled MCT detector. Spectra typically consisted of 128 co-added scans collected at $4-\mathrm{cm}^{-1}$ resolution. Two knife-edge blade apertures, located above and below the sample plane, were adjusted to expose a $200 \mu \mathrm{m} \times 200 \mu \mathrm{m}$ area of the sample to the IR beam for spectral measurements.

During these experiments, IR imaging was accomplished by moving the sample in $200-\mu \mathrm{m}$ increments in either $\mathrm{X}$ - or Y-directions with the manual microscope stage controls. The increment was controlled by visually monitoring the movement of a single paper fiber in the microscope field of view as it passed from one side of the apertured viewing area to just beyond the opposite side. Both sample viewing and IR data collection was accomplished with a $15 \times$ Cassegrainian objective. IR spectra were initially collected in three rows randomly chosen from middle and edge areas of the $25-\mathrm{mm}$ long tipping/cigarette paper seam. Since the step size was $200-\mu \mathrm{m}$, a spectral line across the 4-mm width of the seam was mapped with twenty spectra. A new reference spectrum was collected after each row acquisition. Additional sampling areas of $2 \mathrm{~mm} \times 4 \mathrm{~mm}$ were investigated for a single filter fall-off sample and corresponding control.

\section{RESULTS AND DISCUSSION}

\section{Selection of the Imaging Probe Frequency}

Representative transmission spectra obtained for $200 \mu \mathrm{m} \times 200 \mu \mathrm{m}$ regions of tipping paper glue seams from control samples A and B are shown in Figure 1. The IR spectra of both samples exhibit characteristic bands of paper, paper additives, and adhesive. More specifically, the absorptions observed at 3350- (O-H stretch), 2901(C-H stretch), 1430-1317- (C-H bend, $\mathrm{CH}_{2}$ wag), 1162- 
(antisymmetrical bridge oxygen stretching), 1112- (antisymmetrical in phase ring stretching), and 1061-1035$\mathrm{cm}^{-1}$ (C-O stretch) are characteristic of cellulosic paper (6). The bands observed at 1740- and $1240-\mathrm{cm}^{-1}$ are assigned to the $\mathrm{C}=\mathrm{O}$ and $\mathrm{C}-\mathrm{O}$ stretches of the PVA, respectively. In addition, sample B exhibits bands at 1433and $874-\mathrm{cm}^{-1}$ which are characteristic of a common paper whitener, calcium carbonate(7). Finally, it should be noted that this spectrum versus the sample $A$ spectrum exhibits totally absorbing bands in the $1100-1000-\mathrm{cm}^{-1}$ region. This is attributed to a higher density of the cellulose fibers in the sample. To produce an image of the PVA on the tipping paper, the frequency of $1740-\mathrm{cm}^{-1}$ was selected due to the absence interfering absorbancies from the paper matrix and the lack of significant spectral band saturation.

\section{Semi-quantitative Determination of Adhesive Levels}

To evaluate the adhesive levels along the seams of the defective and acceptable cigarette products, an average IR intensity value for $1740-\mathrm{cm}^{-1}$ was determined for both samples. First, the IR intensities of A and B control samples were measured from spectra acquired in rows across the 4-mm seam width from three positions along the $25-\mathrm{mm}$ seam length. The IR intensity at $1740-\mathrm{cm}^{-1}$ was calculated for each spectrum relative to a baseline drawn between 1800 - and $1520-\mathrm{cm}^{-1}$ using standard instrument software. By plotting the IR intensity versus the spatial position from which the spectrum was measured, maps depicting the adhesive location along the seam were obtained (Figure 2). The observed fluctuations in IR intensity reveal patterned variations in adhesive application; the distance between observed respective low or high IR intensity values is ca. $900 \mu \mathrm{m}$. Negative IR intensity values measured for sample $B$ resulted from a minor absorbance at $1520-\mathrm{cm}^{-1}$ that raised the calculated baseline above the actual spectral baseline. Overall, the average IR intensity values $\left(1740-\mathrm{cm}^{-1}\right)$ for control samples $A$ and $\mathrm{B}$ were the 0.65 and 0.75 absorbance units, respectively.

A composite row image for each control sample was then calculated by averaging the IR intensity values from the three spectral row images with respect to the seam depth location from which each spectrum was measured. Data was collected and reduced in the same manner to generate composite adhesive images of the defective cigarette sample seams. Figure 3 compares the average adhesive row images of $\mathrm{A}$ and $\mathrm{B}$ controls to data from examples of respective defective cigarettes. Although, the data indicates the presence of PVA in the defective seam areas, in all comparisons the amount of PVA present was significantly less than that exhibited by the control samples. The average IR intensity values for defective samples $A$ and $B$ were 0.27 and 0.04 absorbance units, respectively.
Spatial Distribution of the Adbesive on the Tipping Paper Seam

Figure 4 compares IR imagings of a control and filter falloff tipping/cigarette paper seam for $2 \mathrm{~mm} \times 4 \mathrm{~mm}$ regions of brand $A$. The IR intensity values of the control seam image indicated the presence of PVA over the entire seam depth. In contrast, the filter fall-off data show a concentration of PVA along the edge of the seam between 0 and $1600 \mu \mathrm{m}$. A comparison of these three-dimensional images clearly highlights the inconsistent and low levels of PVA that are present in this sample's filter fall-off seam. From the collective FT-IR microspectroscopic data it is evident that PVA had been applied to the tipping paper seam area of the defective cigarettes. However, the quan-

\section{Figure 4.}

Axonometric plots of a brand A control and filter fall-off samples obtained from $2 \mathrm{~mm} \times 4 \mathrm{~mm}$ sampling areas using 200- $\mu \mathrm{m}$ steps.
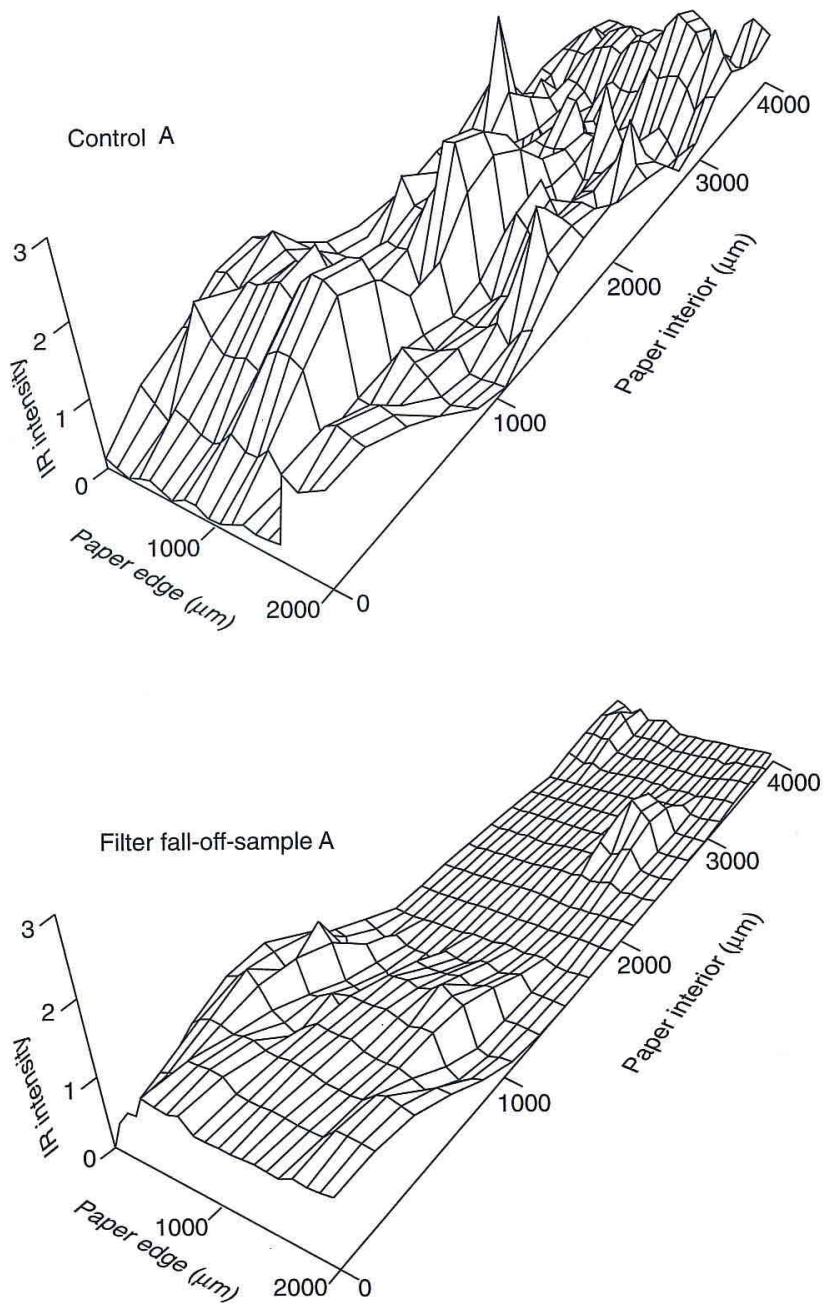
tity of PVA found was much less than that observed in the control and it was not adequately distributed over the coupling area to make an effective seam. Finally, the results of this study demonstrated the usefulness of FT-IR microspectroscopy functional group imaging for evaluating a particular adhesive problem. Due to the wide applicability of IR spectroscopy for both qualitative and quantitative analysis, the utility of this technique in the tobacco industry can certainly be expanded. Future work in our laboratory will explore the characterization of other adhesives, inks, and additives on paper.

\section{REFERENCES}

1. Carl, R. T.: Applications of infrared microimaging to coatings; Microbeam Anal. 24 (1989) 163-165.

2. Harthcock, M. A., and S. C. Atkin: Imaging with functional group maps using infrared microspectroscopy; Appl. Spectrosc. 42 (1988) 449-455.

3. Harthcock, M. A., S. C. Atkin, and B. L. Davis: Infrared microspectroscopy functional group imaging as a probe into the compositional heterogeneity of polymer blends; Microbeam Anal. 23 (1988) 203-206.
4. Harthcock, M. A., and S. C. Atkin: Infrared microspectroscopy: development and applications of imaging capabilities; in Infrared Microspectroscopy: Theory and Applications, edited by R. G. Messerschmidt and M. A. Harthcock, Marcel Dekker, Inc., New York, N. Y., 1988, pp. 21-39.

5. Harthcock, M. A., and S. C. Atkin: Composition mapping with the use of functional group images obtained by infrared microprobe spectroscopy; Microbeam Anal. 22 (1987) 173-176.

6. Sommer, A. J., and J. E. Katon: Infrared and raman microspectroscopy: critical factors in sample purity, preparation and size; Microbeam Anal. 23 (1988) 207-214.

7. Nakamoto, K.: Infrared and raman spectra of inorganic and coordination compounds; John Wiley \& Sons, Inc., New York, N. Y., 1978, p. 129.

\author{
Authors' address: \\ Lorillard Tobacco Company, \\ 420 English Street, \\ Greensboro, NC 27420, U.S.A.
}

